\title{
Emerging Construction Management Issues and Challenges in Kuching
}

\author{
Beatrice Christianus Bidaun, Awang Nasrizal Awang Ali, Fadlin Ahmad Azuwaniza, \\ Muhammad Amirul Othman and Mohd. Amirol Nur Afiq Abd. Razak \\ Faculty of Civil Engineering, Universiti Teknologi MARA, 94300 Kota Samarahan, \\ Sarawak, Malaysia, amighul19@gmail.com
}

\begin{abstract}
Construction industry has been a major contributor to the development in Sarawak, Malaysia. However, difficulties and challenges are inevitable as we move further into a more competitive and modern era. A preliminary study was conducted in the city of Kuching. Interviews with 16 construction companies were carried out which included consultants and contractors. The main purpose is to identify the issues and challenges in Kuching construction industry. Feedbacks from the companies were then analysed and classified into issues and challenges. Recommendation of possible alternatives to minimize the issues and challenges is also discussed. Findings indicate that most companies claimed that financial and economy factor, client's demand and contractual issues are the main issues. Whereas the challenges they are facing are weather and a huge number of Foreign workers. These issues and challenges must be properly addressed to maintain quality in the construction industry.
\end{abstract}

Key words: Construction, Kuching, issues, challenges, difficulties, quality

\section{INTRODUCTION}

Construction industry plays a major role in the development of Kuching, Sarawak. Undeniably, the progressive growth in the industry is also exposed to numerous issues and challenges. Without proper mitigation, it would be a risk for the key players in construction to sustain in the industry. Therefore, the aim of this preliminary study to identify the issues and challenges of construction industry focusing in the city of Kuching.

Problem statements: Anywhere across the globe, the construction industry will face issues and challenges. In a rapid developing city such as Kuching, these issues and challenges are present alongside with situations of construction delay, fatalities and dishonest contractors. There is also proof that the issues have become greater in extent in recent years. Thus, this study identifies the issues and challenges faced by the local construction companies in Kuching.

Objectives: The goal of this study is to investigate aspects that could reduce the efficiency and quality in the construction industry. These will be done through the following objectives:
- To identify issues and challenges that affects the construction industry in Kuching

- To recommend possible alternatives to minimize the issues and challenges in any construction projects

Scope and limitation of study: This research covers construction management issues and challenges in Kuching area. The companies selected are inclusive of both contractors and consultants. Limitation comes in the form of limited data. Due to the several constraints, only 16 companies were available to participate in this study.

Significance of study: The findings highlighted from this study may contribute in improving the construction industry in Kuching. Thus, it helps to enhance the quality of project delivery including infrastructure such as roads, hospitals, schools and other facilities.

Literature review: Many studies have been conducted by the previous researchers to identify issues and challenges in construction industry. Some of the issues and challenges faced by companiesare inclusive of delays, financial difficulties and Foreign workers. Table 1 shows the summary of previous findings.

Corresponding Author: Beatrice Christianus Bidaun, Faculty of Civil Engineering, Universiti Teknologi MARA, 94300 Kota Samarahan, Sarawak, Malaysia, amighul19@gmail.com 
Table 1: Summary of previous findings

Researchers Previous findings

Hasmori et al. (2018) Identified that the highest contributing factor to the delays in Klang Valley construction project is financial difficulties faced by the local contractors

Ullah et al. (2018) The findings highlight the main effects of construction delays are time overrun, cost overrun, dispute, loss of profit and arbitration

Yee et al. (2017) Most of the Foreign workers (respondents) are between 21-40 years old more than half of them are not considered as skilled worker as well as none of them have a higher education level. Most of them acquire training while working. Only a small portion of the respondents did acquire skills by attending training courses

Ikau et al. (2016) Identified that the lack of knowledge or experience in handling construction waste, purchase of materials contrary to specification and inappropriate storage leading to damage and rework in the construction site

Bakhary et al. (2015) Identified the lack of awareness of the site staff to proactively detect claims, inaccessibility or unavailability of relevant documents and conflicts which arises during owner/contractor negotiation are critical problems associated with the process of claim management

Duat (2014) Identified the slow inspection of completed work, inadequate owner finance and slow payment of completed work contributes to the delay in a construction project

Hussin et al. (2013) Identified the issues and challenges in a construction project includes time overrun (70\% of projects), cost overrun (average $14 \%$ of contract cost) and waste generation (approximately $10 \%$ of material cost)

Jabar et al. (2013) Identified delays: poor qualities of final product and cost overrun are the common issues in a construction project

Cheong and Emma (2012) Stated that financial capability of clients is a critical factor to the success of a construction project

Hamid (2011a) The main factor of a huge amount of Foreign workers in the construction industry is due to the ease in travelling policies and also poor enforcement of the authorities

Hamid (2011b) Stated that the recruiting and employment of Foreign labours will result in the outflow of the local currency, the skills and knowledge obtained by the Foreign workers while working in the country will be brought home to their country, the unemployment of the locals will increase and the socials ills caused by the Foreign workers

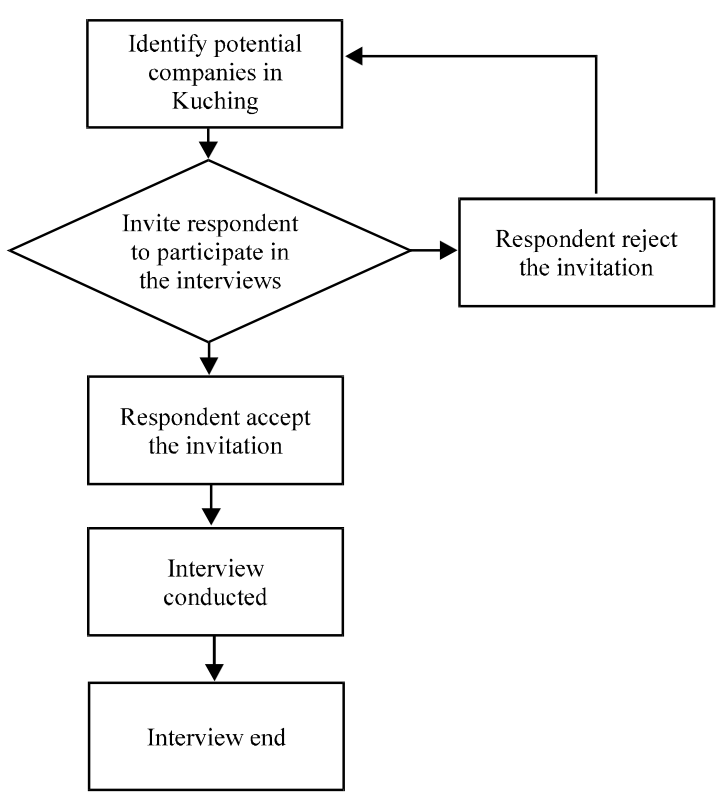

Fig. 1: Flow chart of interview

\section{MATERIALS AND METHODS}

The study was conducted by interviewing the 16 companies which comprises of 6 consultants and 10 contractors companies. The flow of the interview is shown in Fig. 1.

\section{RESULTS AND DISCUSSION}

The data obtained from the interviews are sorted and categorized as issues and challenges. The frequency for each identified issue and challenge is presented in Fig. 2 and 3. Based on data obtained from the interviews conducted, the top three most prominent issue and top four challenges that has been affecting the construction industry are identified.

Issues: The most highlighted issue is financial and economic factor, i.e., the risk of bankruptcy and competition. The former is explained by contractors as due to the penalty when a project is delayed. They claim that some contract terms are having very little exception to the penalty term which does not protect the interest and liability of one stakeholder. The latter is described as the competition among the construction companies. The competition has become increasingly strong with the increase number of advanced companies that utilise new technology which are more efficient.

On a contractor's perspective, client demands sought to be an issue faced by them. Contractors expressed that clients have demanded the use of higher quality and more sophisticated technology in constructing a building. This is seen as a problem as higher quality products are inaccessible to the contractors due to the limitation in budget. For contractual issues, the terms and conditions are not subjected to the consideration of an unforeseen site issue. In the case of an unforeseen site issue occurs, contractors are having a hard time applying for time extension to avoid penalty.

Challenges: The top three identified challenges are i.e., weather, Foreign workers and labour competency. The weather affects the completion of a project particularly 


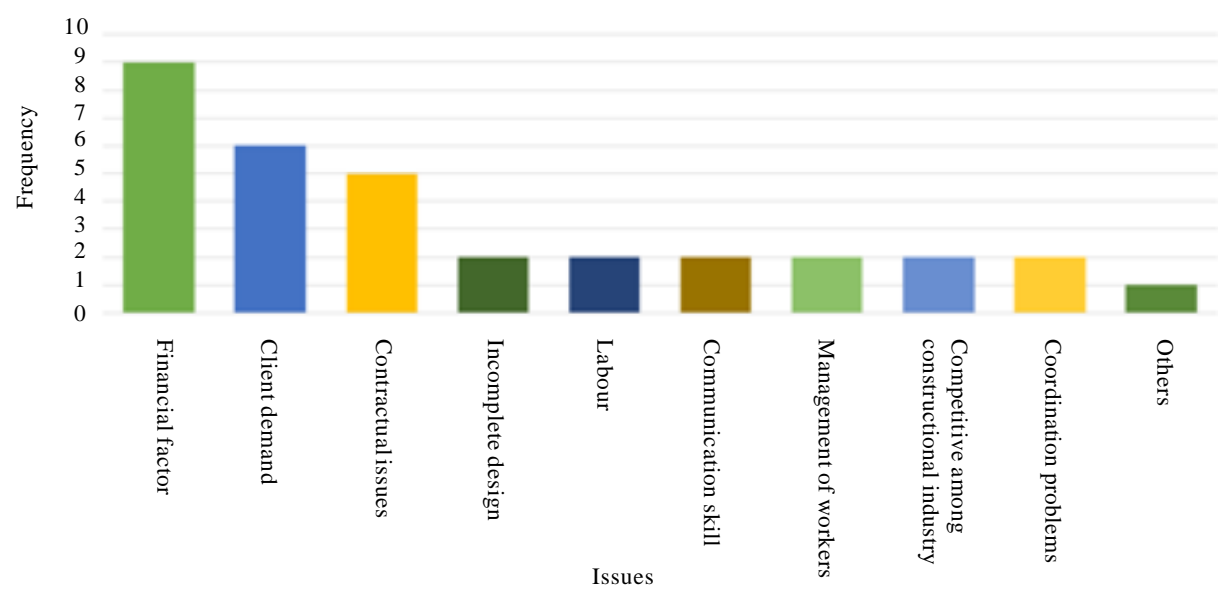

Fig. 2: The issues in construction industry

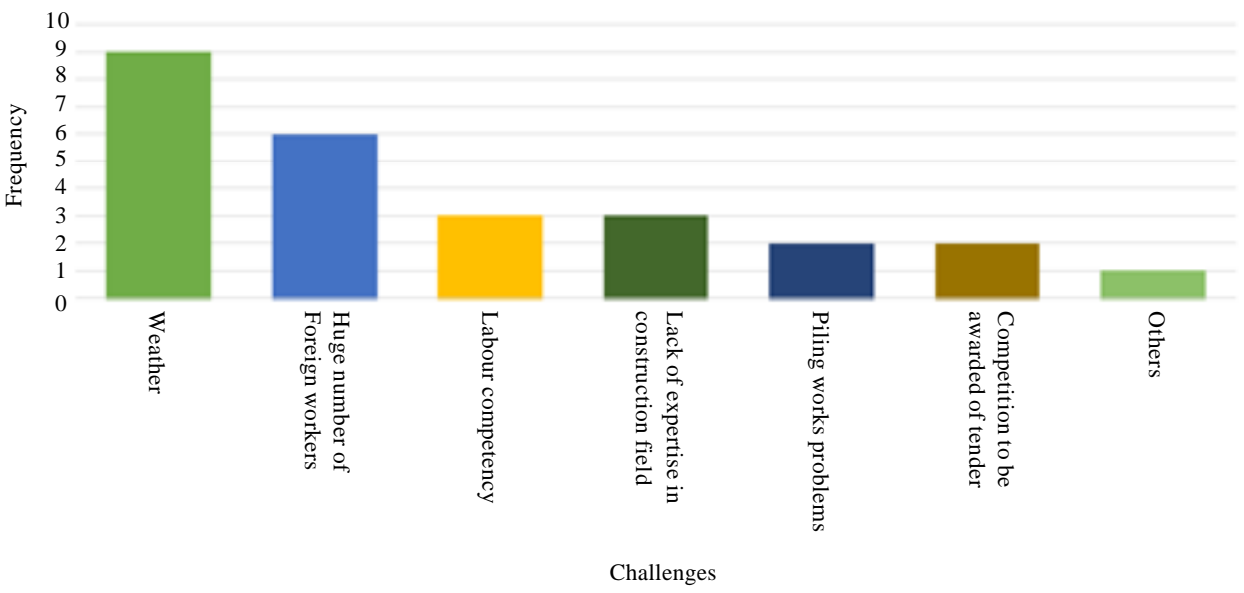

Fig. 3: The challenges in construction industry

during rainy season whereby some construction works have to be postponed. This may cause delays, if not properly planned. Respondents also stated that there are a huge number of Foreign workers in the construction field. Previously in 2016, former Malaysian Deputy Prime Minister has announced the acquisition of 1.5 million workers from Bangladesh to fulfil the employment sector in Malaysian. According to the companies, there is a language barrier between Foreign and local workers. Companies are also having difficulties to hire skilled locals due to the presence of Foreign workers. In terms of labour competency, respondents claimed that there is a lack of capable and skilful manpower in the construction field. This may be due to low criteria requirement in hiring manpower. In addition, the lack of expertise in construction field may also be due to the employment of inexperienced fresh graduates.
The issues and challenges are faced in every construction project by various parties. These must be identified and properly addressed to ensure continuous quality in the construction industry.

Alternatives for improvement: To address financial and economic factor, a proper project planning and scheduling will ensure efficient project cost management and a company will be better prepared with unexpected events by outlining a plan ahead of time (Hasmori et al., 2018). A proper negotiation among industry players including client, contractors and consultant must be done to overcome the issue of client demands. Whilst in contractual issues, the risks and interest of every party should be considered to minimize disagreement or disputes that may occur when something goes out of order.

It is suggested to revise the policy and regulations, application method and payment in order to regulate the 
number of Foreign workers in the industry (Hamid et al., $2011 \mathrm{a}, \mathrm{b}$ ). The lack of skilled manpower on site may be addressed by hiring competent manpower as well as providing regular training and workshops.

\section{CONCLUSION}

Construction industry has been growing rapidly and plays a vital role in the economic growth of Kuching. The construction industries of developing countries will face major challenges in future particularly when we are moving towards rapid development era. Everyone's effort is important towards achieving success of their project.

\section{RECOMMENDATIONS}

Hence, it is recommended that this study should be conducted on a larger scale in the future which should involve more companies to get the actual scenario of the construction industry in Kuching city.

\section{ACKNOWLEDGEMENT}

The researcher would like to thanks to the reviewers for their invaluable comments on this study. Special gratitude is given to those industry practitioners who responded and contributed their valuable input in completing the interviews.

\section{REFERENCES}

Bakhary, N.A., H. Adnan and A. Ibrahim, 2015. A study of construction claim management problems in Malaysia. Procedia Econ. Finance, 23: 63-70.

Cheong Y.Y. and M.N. Emma, 2012. Analysis of factors critical to construction project success in Malaysia. Eng. Constr. Archit. Manage., 19: 543-556.
Duat, H.Y.A.R., 2014. Causes of time delay in construction Sarawak, Malaysia. BS Thesis, Universiti Malaysia Pahang, Gambang, Malaysia.

Hamid, A.R.A., B. Singh, A.M. Yusof and N.A.M. Abdullah, 2011a. The employment of Foreign workers at construction sites. Proceedings of the 2nd International Conference on Construction and Project Management Vol. 15, June 28, 2011, IACSIT Press, Singapore, pp: 126-130.

Hamid, A.R.A., B. Singh, W.Z.W. Yusof, A.M. Yusof and N. Mustafa, 2011b. Problems faced by contractors in managing Foreign workers on construction sites. Proceedings of the 2nd International Conference on Construction and Project Management (IPEDR) Vol. 15, September 16-18, 2011, IACSIT Press, Singapore, pp: 131-135.

Hasmori, M.F., I. Said, R. Deraman, N.H. Abas and S. Nagapan et al., 2018. Significant factors of construction delays among contractors in Klang Valley and its mitigation. Intl. J. Integr. Eng., 10: 32-36.

Hussin, J.M., I.A. Rahman and A.H. Memon, 2013. The way forward in sustainable construction: Issues and challenges. Intl. J. Adv. Appl. Sci., 2: 15-24.

Ikau, R., C. Joseph and R. Tawie, 2016. Factors influencing waste generation in the construction industry in Malaysia. Procedia Soc. Behav. Sci., 234: $11-18$

Jabar, L.I., F. Ismail and A.A. Mustafa, 2013. Issues in managing construction phase of IBS projects. Procedia Social Behav. Sci., 101: 81-89.

Ullah, K., M.S. Khan, M.T. Lakhiar, A.A. Vighio and S. Sohu, 2018. Ranking of effects of construction delay: Evidence from Malaysian building projects. J. Appl. Eng. Sci., 8: 79-84.

Yee, K.C.W.H., A.R.A. Hamid and H.Z.A. Zahari, 2017. Foreign workers composition at construction site. J. Adv. Res. Des., 30: 12-21. 